\title{
Properties of biological and biochemical effects of the Iranian saw-scaled viper (Echis carinatus) venom
}

\author{
Babaie $\mathrm{M}^{1}$, Salmanizadeh $\mathrm{H}^{1}$, Zolfagharian $\mathrm{H}^{2}$, Alizadeh $\mathrm{H}^{1}$ \\ Young Researches and Elites club, Science and Research Branch, Islamic Azad University, Tehran, Iran. \\ m.babaie47@yahoo.com
}

\begin{abstract}
The venom of Echis carinatus is rich in proteins and peptides effective on the hemostatic system. This venom is contains metalloproteinase which convert prothrombin to meizothrombin. The prothrombin activator which leads to the formation of small blood clots inside the blood vessels throughout the body.

To understand the mechanism of the effects of Iranian Echis carinatus venom, the effects of $E$. carinatus on human and Wistar rat plasma, plasma proteins (prothrombin and fibrinogen) and blood coagulation were studied. Proteolytic activity of the crude venom on blood coagulation factors such as prothrombin, partial thromboplastin and fibrinogen times were studied. In the present study the PT test for human plasma was reduced from $13.4 \mathrm{~s}$ $( \pm 0.59)$ to $8.6 \mathrm{~s}( \pm 0.64)$ when human plasma was treated with crude venom (concentration of venom was $1 \mathrm{mg} / \mathrm{ml})$ and for rat plasma PT was reduced from $14.5 \mathrm{~s}( \pm 0.47)$ to $8 \mathrm{~s}( \pm 0.49)$. Some possible biological and biochemical effects of IEc crude venom were investigated. The blood coagulation in human and in rat were investigated in vivo and in-vitro.

In this paper, we show that the procoagulant action of Echis carinatus venom is due in part to a protein component that activates prothrombin and the procoagulant activity on human and rat plasma was evaluated (Tab. 2, Fig. 2, Ref. 31). Text in PDF www.elis.sk.

Key words: biochemical effects, Iranian Echis carinatus, procoagulant activity.
\end{abstract}

The venom of Echis carinatus affects the blood and circulation. E. carinatus venom is very toxic causing severe tissue and organ damage. The venom of Viperidae snakes including the Iranian Echis carinatus (IEc) is rich in proteins and peptides effective on the hemostatic system, i.e., it acts against types of factors involving coagulation and fibrinolysis. In another words, these proteins can be divided into coagulation and anticoagulation and fibrinolytic factors, with many features for their molecular objectives, resistant to physiological inhibitors and stable in vitro and in vivo (1).

In the general classification based on sequence similarities, enzymes include the families of serine proteinases, metalloproteinase, $\mathrm{A}_{2}$ phospholipases, L-amino acid oxidases, nucleases, nucleotidases, and nonenzymatic proteins including lectins of the C-type, disintegrins and 3-finger toxins. These compounds selectively influence different blood coagulation factors and provide the possibility of identifying the characteristics of the structural elements involvedin molecular characteristics $(2,3)$.

${ }^{1}$ Young Researches and Elites club, Science and Research Branch, Islamic Azad University, Tehran, Iran, and ${ }^{2}$ Department of Venomous Animals and Antivenom Production, Razi Vaccine and Serum Research Institute, Karaj, Iran

Address for correspondence: M. Babaie, Young Researches and Elites club, Science and Research Branch, Islamic Azad University, Tehran, Iran. Phone: +98.9125666957

Acknowledgement: Authors would like to thank all members of the Department of Venomous Animals and Antivenom Production. Authors would also like to thank Mr. Askari in enzyme section and Ms. Khame chiyan in Department of serum production for their great help and preparation of this manuscript.
The IEc venom includes metalloproteinases which are prothrombin strong activators. These compounds influence the mammalian's blood coagulation system, especially those which cause acute thrombosis (blood clotting), are mostly major active factors of lethally toxic materials in snake's venoms. The thrombogenic compounds in these venoms show considerable heterogeneity in terms of function and structure. The IEc venom is vastly used in lab studies as a suitable instrument to produce thrombin from prothrombin (4).

Prothrombin is the only protein which is broken in plasma by ecarin, other structures relevant to coagulation factors, ex, factors IX and $\mathrm{X}$ are only rarely influenced by it. Prothrombin is a plasma protein (1- $\alpha, 2$-globin) with the molecular weight of $67800 \mathrm{D}$, exists in natural plasma with the concentration of $150 \mathrm{mg} / \mathrm{l}$ and is an unstable protein which can easily be broken into smaller molecules, one of which is $\alpha$-thrombin with the molecular weight of 33700D ( half the molecular weight of prothrombin) (4).

Yet, besides acting on fibrinogen, thrombin often stimulates blood coagulation by stimulating activation factors V, XII and VIII (and if possible, factor VII). Its complex with thrombomodulin causes the protein $\mathrm{C}$ activation in endothelial cells. This process leads to blood coagulation inhibition by the inactivation of factors $\mathrm{V}$ and VII active form. Furthermore, thrombin often stimulates fibrinolysis and causes clots accumulation (5).

Proteins effective on blood coagulation and existing in the snake venom are classified based on their ability to lengthen or shorten the clotting process into coagulation and anticoagulation proteins (6). 
The methods conducted for clotting in vitro use preclotting toxins which shorten the clotting and decrease coagulation and clotting times, and anticoagulation and anticlotting toxins which delay (lengthen) clotting and coagulation times.

Within recent years, many venom compounds, which influence blood circulation, have been isolated and identified. The study of these factors contributes to discovery and identification of different molecular mechanisms involved in physiological processes. Besides, these studies help us to develop hematological and cardiovascular disorders treatment factors (7).

This study provides the possibility to describe and clarify a series of details on the information about prothrombin activators and some questions which have remained unanswered.

\section{Materials and methods}

\section{Materials}

Venom

The lyophilized Iranian Echis carinatus venom was obtained from the Department of Venomous Animals and Antivenom Production, Razi Vaccine and Serum research institute Karaj, Iran.

\section{Animals}

Experimental animals were were adult male Wistar rats (220$330 \mathrm{~g}$ ) from the colony of Razi Vaccine and Serum research institute Karaj, Iran. The animals were kept at room temperature $\left(20-25^{\circ} \mathrm{C}\right)$ in standard conditions.

\section{Subjects}

Healthy volunteer donors were recruited from the Danesh clinic. Their ages ranged between 30 to 40 years. They were not taking any drugs for at least 3 months before the research.

\section{Other materials}

$\mathrm{CaCl}_{2}, \mathrm{PT}$, PTT kit and fibrinogen was purchased from Fisher Diagnostics (USA). All other chemicals used were of highest quality available.

\section{Methods}

Plasma preparation

Mouse and human citrated blood samples were centrifuged for 15 minutes at 3,000 rpm. The plasma obtained was used for the coagulation tests. The blood sample for this test included $1.8 \mathrm{ml}$ of blood and $0.2 \mathrm{ml}$ of trisodium citrate ( $13 \%$ ) anticoagulant in a ratio of 9 volumes of whole blood to 1 volume of anticoagulant.

Tab. 1. Times for blood coagulation method of Wistar rat plasma.

\begin{tabular}{lccc}
\hline $\begin{array}{l}\text { Blood coagulation } \\
\text { method }\end{array}$ & $\begin{array}{c}\text { Mean of test } \\
( \pm \text { SD) }\end{array}$ & $\begin{array}{c}\text { Min and max } \\
\text { (values) }\end{array}$ & $\begin{array}{c}\text { Number of Tests } \\
(\text { rat })\end{array}$ \\
\hline CT (s) & $120 \pm 1.25$ & $110-131$ & 20 \\
BT (s) & $94 \pm 3.49$ & $70-130$ & 20 \\
PT (s) & $14.5 \pm 1.2$ & $12-18$ & 17 \\
APTT (s) & $24 \pm 4.4$ & $20-27$ & 17 \\
FT (s) & $195 \pm 4.1$ & $170-230$ & 17 \\
\hline
\end{tabular}

\section{Blood coagulation method \\ Clotting Time (CT)}

To measure the blood clotting time, Rat's tail was placed in hot water $\left(40{ }^{\circ} \mathrm{C}\right)$ for $1 \mathrm{~min}$. After this time, rat $>$ s tail was dried and a small incision was made on it with a razor blade. In each micro hematocrit glass capillary tubes $25 \mu \mathrm{L}$ of capillary blood was collected. At the moment of the first contact of blood with hematocrit tubes time measurement was started. The hematocrit tube alternately tilted to the left and right with $+60^{\circ}$ and $-60^{\circ}$ angles with respect to the horizontal plane until blood ceased to flow (8).

\section{Bleeding time (BT)}

Bleeding times of the rats and humans were measured as follows:

Rat's tail was placed in hot water $\left(40^{\circ} \mathrm{C}\right)$ for $1 \mathrm{~min}$. After a minute, Rat>s tail was dried and a small incision was made on them with a scalpel. Time is recorded when the first drop touched the filter paper. It was checked at $30 \mathrm{~s}$ intervals until bleeding stopped. For humans, the fingers are sterilized and pricked with a lancet, preferably on the fingertip. The prick is about 3-4 mm deep. Wipes the blood every 30 seconds with a filter paper. BT ceases when bleeding stopped (8-10).

\section{Prothrombin time (PT)}

PT determination was obtained according to reported methods. In the beginning, citrated plasma and PT reagent get out from refrigerators until reaching the room temperature $\left(20^{\circ}-25^{\circ} \mathrm{C}\right)$. Citrated plasma and PT reagent (containing $200 \mu \mathrm{L}$ of thromboplastin-D solution and $100 \mu \mathrm{L}$ of the citrated plasma) was incubated for $1 \mathrm{~min}$ at $37^{\circ} \mathrm{C}$. When the clot was observed, the PT time was recorded $(11,12)$.

\section{Activated partial thromboplastin time (APTT)}

PTT reagents were brought to the lab until reaching the room temperature $\left(20-25^{\circ} \mathrm{C}\right)$. Firs, $100 \mu \mathrm{l}$ of partial thromboplastin was poured into a glass tube, than $100 \mu \mathrm{l}$ plasma was added. This compound was placed in Bain-marie for $3 \mathrm{~min}$ at $37^{\circ} \mathrm{C}$. Finally, $100 \mu \mathrm{l}$ of $\mathrm{CaCl}_{2}$ was added to it. Simultaneously, the chronometer was started. After shaking the tube for about 20 seconds in Bainmarie, the tube was ejected from water and it was searched for the clot. The time required for clot formation was recorded (12).

\section{Fibrinogen time (FT)}

Fibrinogen is one of the plasma basic proteins with normal levels of $180-400 \mathrm{mg} / \mathrm{dl}$. It is an acute phase protein; its level in

Tab. 2. Times for blood coagulation method of human plasma.

\begin{tabular}{lccc}
\hline $\begin{array}{l}\text { Blood coagulation } \\
\text { method }\end{array}$ & $\begin{array}{c}\text { Mean of test } \\
( \pm \text { SD) }\end{array}$ & $\begin{array}{c}\text { Min and max } \\
\text { (values) }\end{array}$ & $\begin{array}{c}\text { Number of Tests } \\
\text { (human) }\end{array}$ \\
\hline CT (s) & $490 \pm 4.62$ & $290-700$ & 12 \\
BT (s) & $245 \pm 3.53$ & $140-360$ & 12 \\
PT (s) & $13.4 \pm 0.59$ & $12-15$ & 10 \\
APTT (s) & $34.5 \pm 1.1$ & $28-40$ & 10 \\
FT (s) & $284 \pm 2.3$ & $200-390$ & 12 \\
\hline
\end{tabular}


necrotic tissue within $24 \mathrm{~h}$ will thus substantially increase. This test was conducted according to the Clauss method $(13,14)$. Half an hour before the test all reagents are taken out of refrigerator so that they reach lab temperature $\left(20-25^{\circ} \mathrm{C}\right)$.

1. Sample dilution: $0.1 \mathrm{ml}$ of plasma and $0.9 \mathrm{ml}$ of Reagent A (diluting buffer) are mixed. A dilution of $1: 10$ of plasma will thus be obtained.

2. Incubation: $0.2 \mathrm{ml}$ of diluted plasma is incubated in a hemolysis tube for $2 \mathrm{~min}$ at $37^{\circ} \mathrm{C}$ Bain-marie.

3. Clotting: Reagent B (thrombin) should always be kept at lab temperature $\left(20-25^{\circ} \mathrm{C}\right)$. It shall never be incubated at $37^{\circ} \mathrm{C}$. After 2 min of incubation, $0.1 \mathrm{ml}$ of Reagent $\mathrm{B}$ is added to diluted plasma. At the same time, a chronometer is switched on. The tube is shaken to search for the clot. As soon as the first signs of clotting or fibrin thin strands are observed, the chronometer will be stopped and the time is documented.

4. Reading the amount of fibrinogen. Using the Time Table included in the test kit, the amount of fibrinogen will be specified in terms of the coagulation time obtained.

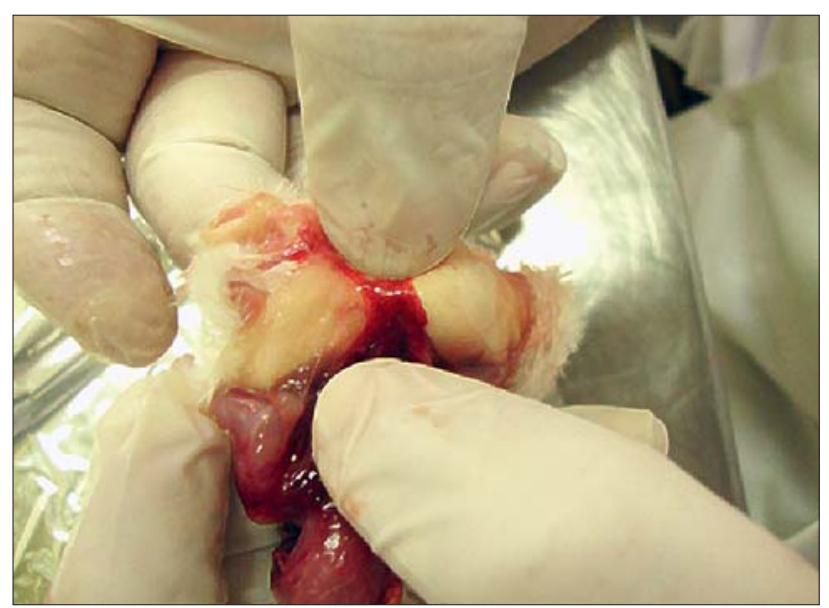

Fig. 1. Hemorrhagic point of Wistar rat.

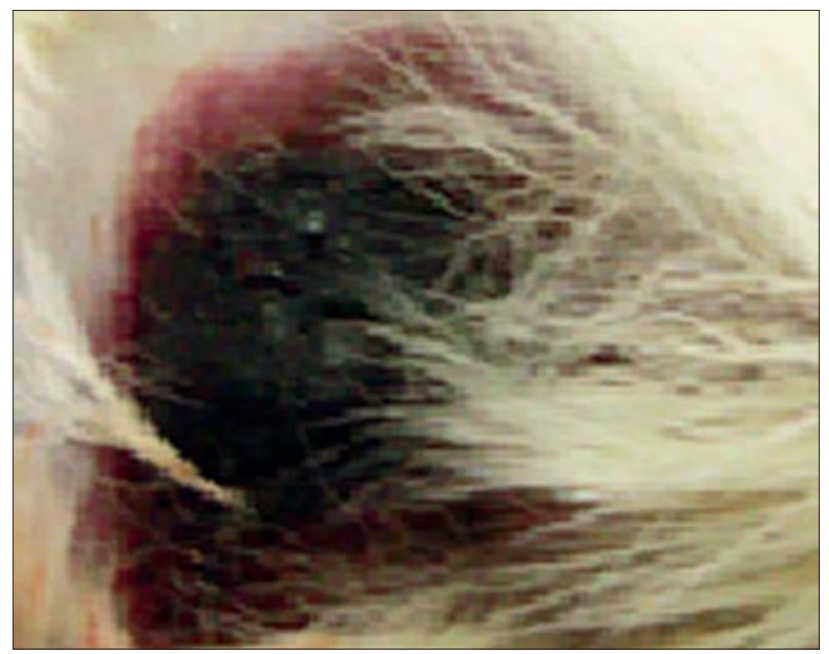

Fig. 2. Thick dermal necrosis damage in Wistar rat.

\section{Assessment of hemorrhagic activity}

Hemorrhagic activity was performed according to the method of the skin test procedure of Kondo et al. The amount of $0.1 \mathrm{ml}$ of the IEc crude venom was subcutaneously injected into the depilated skin of the back of rats at the different concentration to assess the IEc hemorrhagic activity. After $24 \mathrm{~h}$, the rats were suffocated due to gas inhalation in a special container. The rat's hemorrhagic points generated subcutaneously were observed and determined. The control group was injected with $0.1 \mathrm{ml}$ of normal physiological saline instead of the venom $(15,16)$.

\section{Assessment of necrosis activity}

$0.1 \mathrm{ml}$ of the IEc crude venom was intradermally injected to the hind legs of rats to assess the necrosis activity. After three days, necrosis damage due to the venom was observed and examined (14-16).

\section{Results}

All results of blood coagulation tests (CT, BT, PT, APTT and FT) are listed in Tables 1 and 2.

The present study showed that crude venom of Iranian Echis carinatus can accelerate the blood coagulation pathway. Our results indicated that as the concentration of venom increased, the PT of plasma decreased. With $1 \mathrm{mg} / \mathrm{ml}$ concentration of venom the clotting time of plasma decreased from $13.4 \mathrm{~s}( \pm 0.64)$ to 8.6 $\mathrm{s}( \pm 0.59)$. And the clotting time of plasma decreased from $14.5 \mathrm{~s}$ $( \pm 0.47)$ to $8 \mathrm{~s}( \pm 0.49)$ when mice plasma was treated with crude venom $(1 \mathrm{mg} / \mathrm{ml})$.

The results of hemorrhagic activity indicate that after peeling and taking the skin off the animals, the subcutaneous hemorrhagic points with $10 \mathrm{~mm}$ damage were observed as shown in Figure 1. This damage was caused by the injection of $10 \mu \mathrm{g} / \mathrm{ml}$ of IEc venom. With injection of IEc venom, after 3 days, $5 \mathrm{~mm}$ thick dermal necrosis damage was observed (Fig. 2).

\section{Discussion and conclusion}

The identification and investigation of the compounds in snake's venoms is very important and intended by scientists. Viperid snake venoms are identified to contain components with coagulant activity which can affect the hemostatic and blood coagulation system. Among the most significant compounds existing in this snake's venom are prothrombin activators. The venom of Viperidae snakes, including the Iranian Echis carinatus, is rich in compounds which can have many applications in medicine and pharmaceutics (17).

Research on prothrombin activators shows that a key phase in blood coagulation is targeted by two major classes of proteinases, the study of which reveals different aspects so that the study of metalloproteinases (prothrombin activators groups A and B) helps us to understand the determination of the substrate features whereas the study of serine proteinases (prothrombin activators groups $\mathrm{C}$ and D) helps us to understand the relations between mammalians coagulation factors structure, function, molecular details of pro- 
thrombinase complex formation in the coagulation system and the evolution of new anticoagulation factors (18).

The results described herein clearly show that the venom of IEc contains a hitherto novel type of prothrombin activator. This finding necessitates reconsideration of the classification of exogenous prothrombin activators. We propose that the previously defined group 1 enzymes be divided into two subgroups, i.e. the ecarin-like $\left(\mathrm{Ca}^{2+}\right.$-independent) metalloproteinases (perhaps termed group 1A), such as aharin from Agkistrodon halys pallas and prothrombin activator from Bothrops atrox (19) and the carinactivaselike ( $\mathrm{Ca}^{2+}$-dependent) enzymes (group 1B) such as carinactivase-1 from Echis carinatus (4).

All the venom preparations from Echis snakes contained both ecarin-like and carinactivase-like activators, although the total activities as well as the relative abundance of the two enzymes varied depending upon the source. However, CA-1 appears to be a hybrid protein that is well adapted for the efficient and selective activation of prothrombin in the plasma of target animals after envenomation (20-22).

It can be interpreted that the IEc venom will activate the coagulation system by more than $100 \%$. This coagulation system quick activation occurs outside the animal's body and brings about clinical effects leading to death such as coagulopathies and DIC. Prothrombin activating enzymes (similar to ecarin) can be used as an important lab instrument to analyze the blood of the patients suffering from hepatopathies. The value of these enzymes is that, despite $\mathrm{FX}_{\mathrm{a}}$, independently with no need for any cofactors even with no need for FV, they act on carboxilated or non- carboxilated prothrombin. Even if there is a disorder in FV, the level of prothrombin in patient's blood can thus be measured using these enzymes $(23,24)$.

PT test results showed that the sensitivities of the three thromboplastins used were very different in the rat. The mean values recorded for humans and rats were very similar.

About APTT, according to the manufacturer's instructions and using the same reagents, times were much shorter in rat $(24 \pm 4.4$ $\mathrm{s})$ than in humans $(34.5 \pm 1.1 \mathrm{~s})$ at a significant level $(\mathrm{p}<0.005)$.

Using standard reagents for human, signification of PT and APTT were standardized in rat, taking into account all the intrinsic and extrinsic factors of clotting. It is worth mentioning that the sensitivity response of different thromboplastins depends on the tissues, species, and collection methods, which will be reflected in shorter or longer clotting times. The mean of fibrinogen test in the rat was lower $(195 \pm 4.1)$ than the normal human established range $(284 \pm 2.35)$.

Intense local damage caused due to intoxication by Viperidae and Crotalidae snakes venoms have a complex identity including pain, hemorrhage, tissue necrosis and edema, mostly causing the loss of tissue or mutilation. The formation of such pathological complex damage is relevant to multiple biological functions taking place by one or some factors operating independently or in cooperation with each other.

The occurrence of hemorrhage is one of the most common complications of the subcutaneous injection of venoms especially those of Viperidae and Crotalidae snakes. Among these, Elapidea family enjoys a strong hemorrhage effect, whose hemorrhage factor has been derived $(25,26)$.

In less acute cases, hemorrhage is limited to dermal and sub dermal tissues in the injection region. In acute cases, the covering tissue (epithelium) hemorrhage widens and covers the muscular layer. Hemorrhage often occurs in several organs such as the brain, heart, lungs, intestines and kidney. Some researchers believe that hemorrhage due to the snakes bite is caused by damage to the blood vessels wall by venoms specific elements (hemorrhages), coagulation disorders by venom other components (coagulation and anticoagulation factors) and thrombocytopenia. The expression hemorrhagin or hemorrhagic factors means the venom factors which cause hemorrhage by a direct action on the blood vessels wall and which differ from factors that influence hemostasis and blood coagulation.

For the IEc venom, this hemorrhage or bleeding was thus observed after the crude venom injection (Fig. 1), hemorrhage occurring in the presence of the snake venom metalloproteinases. The metalloproteinases of viperidae snakes venoms including that of the IEc are endoproteolytic enzymes whose catalytic activity depends on the zinc ions. Beside the role of metalloproteinases in the prey digestion and destruction, they show several other biological effects including the formation of hemorrhage, precoagulation, anticoagulation and antiplatelet effects.

With a minor correction to the method of Kondo et al a dermal (skin) test was conducted and its result was assessed $(14,27)$. In this method, (220-330 g) mice were used. The IEc crude venom was subcutaneously injected at different concentration. After 24 hours, the tested mice were suffocated by gas inhalation. They were further peeled off and the subcutaneous hemorrhagic region was measured. The minimum amount of protein which generates $10 \mathrm{~mm}$ thick hemorrhagic region was specified and determined as the minimum hemorrhagic dose. The IEc crude venom at the concentration of $10 \mu \mathrm{g} / \mathrm{ml}$ let to the formation of a $10 \mathrm{~mm}$ thick hemorrhagic region. This concentration was considered as the minimum hemorrhagic dose which is less than LD 50 (lethal dose $50 \%$ ) of the IEc crude venom $(11.2 \mu \mathrm{g} / \mathrm{ml})$. Also, the presence of metalloproteinases was proved as a group of the effective enzymes existing in the IEc venom.

The proteinase isolated from viper lebetina, $\mathrm{VLH}_{2}$, also showed fibrinolytic and hemorrhagic activities. This hemorrhagic metalloproteinases have myotoxic activities (28). Other hemorrhagic factors have been derived from different venoms (29-31). Their effects mechanisms have however been less discussed. In the common terminology of pathology, necrosis is related to performances which lead to the death of a group of cells. The venoms of Viperidae snakes including the IEc are intensely necrotic (Fig. 2).

Over the past 20 years, many metalloproteinases have been isolated from snake venom with a wide variety of biological activities, including hemorrhagic, fibrinogenolytic, and antiplatelet effects, as well as activation of prothrombin and factor X. It is important to note that all the metalloproteinases that activate blood coagulation factors, such as prothrombin or factor $\mathrm{X}$, are high-molecular-weight metalloproteinases and belong to either class III or IV (19). 
According to our results, the prothrombin activator from Echis carinatus rapidly converts prothrombin into meizothrombin. This may be due to the partial loss of the biological activity of the enzyme.

\section{References}

1. Kini RM. Serine proteases affecting blood coagulation and fibrinolysis from snake venoms. Pathophysiol. Haemost Thromb 2005; 34 (4-5): 200-204.

2. Sajevic T, Leonard A, Križaj I. Haemostatically active proteins in snake venoms. Toxicon. 2011; 57 (5): 627-645.

3. Braud S, Bon C, Wisner A. Snake venom proteins acting on hemostasis. Biochimie 2000; 82: 851-859.

4. Yamada D, Sekiya F, Morita T. Isolation and characterization of carinactivase, a novel prothrombin activator in Echis carinatus venom with a unique catalytic mechanism. J Biol Chem 1996; 271 (9): 5200-5207.

5. Tokunaga F, Nagasawa K, Tamura S, Miyata T, Iwanaga S, Kisiel $\mathbf{W}$. The factor $\mathrm{V}$-activating enzyme (RVV-V) from Russell's viper venom. Identification of isoproteins $\mathrm{RVV}-\mathrm{V} \alpha,-\mathrm{V} \beta$, and $-\mathrm{V} \gamma$ and their complete amino acid sequences. J Biol Chem 1988; 263: 17471-17481.

6. Lee WH, Zhang Y, Wang WY, Xiong YL, Gao, R. Isolation and properties of a blood coagulation factor $\mathrm{X}$ activator from the venom of king cobra (Ophiophagus hannah). Toxicon 1995; 33: 1263-1276.

7. Rao VS, Swarup S, Kini, RM. The nonenzymatic subunit of pseutarin $\mathrm{C}$, a prothrombin activator from eastern brown snake (Pseudonaja textilis) venom, shows structural similarity to mammalian coagulation factor V. Blood 2003; 102: 1347-1354.

8. Manzano AG, Llaven JG, Llemimi C, Poo CR. Standardization of rat blood clotting tests with reagents used for humans. Proc West Pharmacol Soc 2001; 44: 153-155.

9. Caterina RD, Lanza M, Manca G, Strata GB, Maffei S, Salvatore L. Bleeding time and bleeding: an analysis of the relationship of the bleeding time test with parameters of surgical bleeding. Blood 1994; 84: $3363-3370$

10. Kasper CK, Rapaport SI. Bleeding times and platelet aggregation after analgesics in hemophilia. Ann Intern Med 1972; 77 (2): 189-193.

11. Ghorbanpur M, Zare Mirakabadi A, Zokaee F, Zolfagharian H, Rabiei H. Purification and partial characterization of a coagulant serine protease from the venom of the Iranian snake Agkistrodon halys. J Venom Anim Toxins incl Trop Dis 2009; 15 (3): 411-423.

12. Rizzo F, Papasouliotis K, Crawford E, Dodkin S, Cue S. Measurement of prothrombin time (PT) and activated partial thromboplastin time (APTT) on canine citrated plasma samples following different storage conditions. Res Vet Sci 2008; 85 (1): 166-170.

13. Clauss A. Gerinnungsphysiologische schnell methode zur bestimmungs des fibringens. Acta Haematol 1957; 17: 237-246.

14. Mackie IJ, Kitchen S, Machin SJ, Lowe GD. Guidelines on fibrinogen assays. Br J Haematol 2003; 121: 396-404.

15. Kondo H, Kondo S, Ikezawa H, Murataata R. Studies on the quantitative method for determination of hemorrhagic activity of Habu snake venom. Jpn J Med Sci Biol 1960; 13: 43-51.

16. Sells PG. Animal experimentation in snake venom research and in vitro alternatives. Toxicon 2003; 42: 115-133.
17. Joseph JS, Chung MC, Jeyaseelan K, Kini RM. Amino acid sequence of trocarin, a prothrombin activator from Tropidechis carinatus venom: its structural similarity to coagulation factor Xa. Blood 1999; 94 (2): 621-631.

18. Kini RM. The intriguing world of prothrombin activators from snake venom. Toxicon 2005; 45: 1133-1145.

19. Gao R, Kini RM, Gopalakrishnakone P. A novel prothrombin activator from the venom of Micropechis ikaheka: isolation and characterization. Arch Biochem Biophys 2002; 408 (1): 87-92.

20. Silva MB, Schattner M, Ramos CR, Junqueira-De-Azevedo ILM, Guarnieri MC, Lazzari MA et al. A prothrombin activator from Bothrops erythromelas (jararaca-da-seca) snake venom: characterization and molecular cloning. Biochem J 2003; 369: 129-139.

21. Berger M, Pinto A, Guimarães JA. Purification and functional characterization of bothrojaractivase, a prothrombin-activating metalloproteinase isolated from Bothrops jararaca snake venom. Toxicon 2008; 51 (4): 488-501.

22. Petrovan RJ, Govers-Riemslag JW, Nowak G, Hemker HC, Rosing $\mathbf{J}$, Tans $\mathbf{G}$. Purification and characterization of multisquamase, the prothrombin activator present in Echis multisquamatus venom. Thromb Res 1997; 88 (3): 309-316.

23. Howes J, Kamiguti A, Theakston RMC, Wilkinson M, Laing G. Effects of three novel metalloproteinases from the venom of the West African saw-scaled viper, Echis ocellatus on blood coagulation and platelets. Biochim Biophys Acta 2005; 1724: 194-202.

24. Marcia BS, Mirta S, Celso RR, Inacio LM, Miriam CG, Maria AL et al. A prothrombin activator from Bothrops erythromelas (jararaca-daseca) snake venom: characterization and molecular cloning. Biochem J 2003; 369: 129-139.

25. Takeya H, Nishida S, Miyata T, Kawada S, Saisaka Y, Morita T, Iwanaga S. Coagulation factor X activating enzyme from Russell's viper venom (RVV-X). A novel metalloproteinase with disintegrin (platelet aggregation inhibitor)-like and C-type lectin-like domains. J Biol Chem 1992; 267: 14109-14117.

26. Siigur E, Tonismagi K, Trummal K, Samel M, Vija H, Subbi J, Siigur J. Factor X activator from Vipera lebetina snake venom, molecular characterization and substrate specificity. Biochim Biophys Acta 2001; 1568: 90-98.

27. Kisiel W, Kondo S, Smith KJ, McMullen BA, Smith LF. Characterization of a protein $\mathrm{C}$ activetor from Agkistrodon contortrix contortrix venom. J Biol Chem 1987; 262: 12607-12613.

28. Ghorbanpur M, Zare Mirakabadi A, Zokaee F, Zolfagarrian H. Identification and partial purification of an anticoagulant factor from the venom of the Iranian snake Agkistrodon halys. J Venom Anim Toxin incl Trop Dis 2010; 16 (1): 96-106.

29. Gay CC, Leiva LC, Marunak S, Teibler P, Acosta de Pérez O. Proteolytic, edematogenic and myotoxic activities of a hemorrhagic metalloproteinase isolated from Bothrops alternatus venom. Toxicon 2005; 46: 546-554.

30. Stroka A, Donato JL, Bon C, Hyslop S, De Araújo AL. Purification and characterization of a hemorrhagic metalloproteinase from Bothrops lanceolatus (Fer-de-lance) snake venom. Toxicon 2005; 45: 411-420.

31. Leonardi A, Fox JW, Trampus-Bakija A, Kri-zaj I. Ammodytase, a metalloprotease from Vipera ammodytes ammodytes venom, possesses strong fibrinolytic activity. Toxicon 2007; 49: 833-842.

Received February 1, 2013. Accepted March 24, 2014. 